\title{
The current state and future prospects of the fundamental research on pediatric otorhinolaryngology: an analysis of application and funding data of the National Natural Science Foundation of China from 2009 to 2019
}

\author{
Yihong Liu, Xiaobin Zhang \\ National Natural Science Foundation of China, Beijing, China \\ Contributions: (I) Conception and design: X Zhang; (II) Administrative support: X Zhang; (III) Provision of study materials or patients: All authors; (IV) \\ Collection and assembly of data: Y Liu; (V) Data analysis and interpretation: All authors; (VI) Manuscript writing: All authors; (VII) Final approval of \\ manuscript: All authors. \\ Correspondence to: Xiaobin Zhang. Department of Health Sciences, National Natural Science Foundation of China, Beijing 100085, China. \\ Email: zhangxb@nsfc.gov.cn.
}

Background: This study aimed to summarize the current situation and deficiencies of the fundamental research on pediatric otolaryngology-head and neck science. It is hoped that the results can provide support for the long-term development of the basic research on this subject.

Methods: Information concerning the applications to and funding from the National Natural Science Foundation of China (NSFC) for otolaryngology-head and neck from 2009 to 2019 was collected and analyzed.

Results: In the past 10 years, pediatric otolaryngology-head and neck science received 150 applications, accounting for $2.92 \%$ of all applications for otolaryngology-head and neck science. Ultimately, 20 projects were funded, accounting for $2.17 \%$ of all the funded projects. There were 88 applications for children's ear science and hearing-related research, accounting for $58.67 \%$ of the applications for pediatric otolaryngologyhead and neck science. Furthermore, 14 approved grants focused on cochlear implants and the genetics and mechanisms of deafness. There were 25 applications related to children's nasal science, particularly allergic rhinitis, accounting for $16.67 \%$ of the total applications. Of these, 4 applications were funded, and these mainly focused on the disease regulation and pathogenesis of allergic rhinitis. A total of 30 applications related to children's laryngopharyngeal diseases, accounting for $20 \%$ of the applications, mainly focused on obstructive sleep apnea syndrome (OSAS), adenoid hypertrophy, and tonsil hypertrophy, with only 1 application being funded. The scientific research on children's head and neck was mainly related to laryngeal papilloma and lymphatic vascular malformation, with 7 projects being applied for and 2 being funded.

Conclusions: The fundamental research of pediatric otolaryngology-head and neck science in China is at a relatively weak level and lags behind the average level of the discipline. There are relatively few basic researchers engaged in pediatric otolaryngology-head and neck science, and the dominant research units are relatively concentrated. The basic research of children's ear science is relatively advanced in each subspecialty, so the basic research on children's unique congenital and hereditary diseases should be further strengthened.

Keywords: Pediatric otorhinolaryngology; National Natural Science Foundation of China (NSFC); fundamental research

Submitted Apr 26, 2020. Accepted for publication Oct 20, 2020.

doi: 10.21037/atm-20-6487

View this article at: http://dx.doi.org/10.21037/atm-20-6487 


\section{Introduction}

Otorhinolaryngology is a surgical subspecialty within medicine that deals with conditions of the ear, nose, and throat (ENT) and related structures of the head and neck. Recently, more and more funding and technology strength are put into the fundamental researches on otorhinolaryngology. Pediatric otorhinolaryngology is an important sub-professional discipline of otorhinolaryngology. Children's physical and psychological development differs from that of adults, and children cannot simply be characterized as "little adults". In the initial stages of the full life cycle, children's health warrants strict attention. Over the past ten years, driven by the demand for clinical precision and individualized diagnosis and treatment, basic scientific research on pediatric otolaryngology-head and neck has been initiated (1). The present study retrospectively analyzed the applications to and funding provided by the National Natural Science Foundation of China (NSFC) in the field of otolaryngology-head and neck science from 2009 to 2019, and summarized the current situation and deficiencies of the fundamental research in pediatric otolaryngology-head and neck science. By discussing the trends in grants that appear, it is hoped that support for the long-term development of basic research on this subject can be provided.

\section{Methods}

This study conducted a retrospective analysis of the application and funding projects of the NSFC in the field of otorhinolaryngology (H13) from 2009 to 2019. The extracted information included project name, supporting institution, application code, funding type, project duration, start and end date, funding status, funding amount, subscientific direction, etc. All the original data were put into the excel table and analyzed. Each group of data was used graphpad 7.0 software to draw, and integrated the icons through Adobe Illustrator CC 2017 software. Statistical analysis was undertaken using SPSS 23.0. Comparisons were done with the Chi-square test and Fisher's exact test for categorical parameters, while with Student's $t$ test or analysis of variance (ANOVA) test for continuous variables. A 2 -sided $\mathrm{P}<0.05$ was considered to be statistically significant.

\section{Results}

From 2009 to 2019, otolaryngology-head and neck science
(H13) received a total of 5,103 applications with 922 projects being funded, including general programs, youth programs, and regional science fund programs, and a funding rate of $18.07 \%$. The amount of funding given was 45.509 million yuan (only direct costs were included after 2014). Pediatric otolaryngology-head and neck science received 150 applications in total, accounting for $2.92 \%$ of all applications for otolaryngology-head and neck science. Ultimately, 20 projects were funded, accounting for $2.17 \%$ of all the funded projects. The amount of funding given was 10.17 million yuan, accounting for $2.28 \%$ of the total funding (Table 1).

From 2009 to 2013, the indexes of the projects, including the application number, grant number, funding rate, and funding amount, continued to increase in the field of otolaryngology-head and neck science. However, the grant numbers in otolaryngology-head and neck science for children did not increase significantly, and only 4 children's projects given were given annual funding. The funding rate of pediatric otolaryngology-head and neck science was significantly lower than the overall level of the discipline. In 2010 and 2012, no children's project received funding. With the declining rate of funding from 2014 to 2019 and a basically stable funding amount in the general field of otolaryngology-head and neck science, the internal funding rate of children's projects was constantly lower than that of the general field. Since 2013, the proportion of the number of pediatric otolaryngology-head and neck science funding projects to the total number of funding projects has basically stabilized at about $2 \%$ (Table 2) (2). The top 3 research areas in the period from 2009 to 2019 in otolaryngology-head and neck science project were genetic and developmental diseases of otolaryngologyhead and neck, olfactory nose and vestibular diseases, and disorders in hearing and balance. For other scientific problems of ear, nose, and throat (ENT) diseases, the funding rate was $41.67 \%$, exceeding the overall funding rate of the disciplines. However, in other fields, the funding rates were significantly lower than the overall funding rate of the disciplines. For other scientific issues in the field of pediatric otolaryngology-head and neck, the funding rate was as high as $11.63 \%$, which was higher than the others in this field; meanwhile, there was no successful funding for new technologies in the diagnosis and treatment of ENT diseases (Table 3). Except for 4 regional science projects, the areas where projects of pediatric otolaryngology-head and neck science received funding were mainly concentrated in Beijing, Shanghai, Guangdong, Shandong, and Shanxi, and 
Table 1 Information of the applications to and funding from the NSFC for otolaryngology-head and neck science (2009-2019)

\begin{tabular}{|c|c|c|c|c|c|c|c|c|}
\hline \multirow[b]{2}{*}{ Type } & \multicolumn{4}{|c|}{ Otolaryngology-head and neck science } & \multicolumn{3}{|c|}{$\begin{array}{l}\text { Pediatric otolaryngology-head and neck } \\
\text { science }\end{array}$} & \multirow{2}{*}{$\begin{array}{l}\text { Funding } \\
\text { rate of } \\
\text { children's } \\
\text { programs }\end{array}$} \\
\hline & $\begin{array}{c}\text { Application } \\
\text { number }\end{array}$ & $\begin{array}{l}\text { Funding } \\
\text { number }\end{array}$ & $\begin{array}{l}\text { Funding } \\
\text { rate (\%) }\end{array}$ & $\begin{array}{c}\text { Funding } \\
\text { amount } \\
\text { (millions) }\end{array}$ & $\begin{array}{l}\text { Application } \\
\text { number }\end{array}$ & $\begin{array}{l}\text { Funding } \\
\text { number }\end{array}$ & $\begin{array}{l}\text { Funding } \\
\text { amount } \\
\text { (millions) }\end{array}$ & \\
\hline General program & 2,523 & 459 & $18.91 \%$ & 255.595 & 65 & 8 & 433 & $1.68 \%$ \\
\hline Regional program & 367 & 67 & $18.46 \%$ & 25.82 & 12 & 4 & 153 & $5.97 \%$ \\
\hline Other & 218 & 66 & $21.10 \%$ & 96.304 & 3 & 1 & 290 & $2.17 \%$ \\
\hline Total & 5,103 & 922 & $18.07 \%$ & 445.509 & 150 & 20 & 1,017 & $2.28 \%$ \\
\hline
\end{tabular}

NSFC, National Natural Science Foundation of China.

Table 2 Annual information of the application and funding of the NSFC for otolaryngology-head and neck science

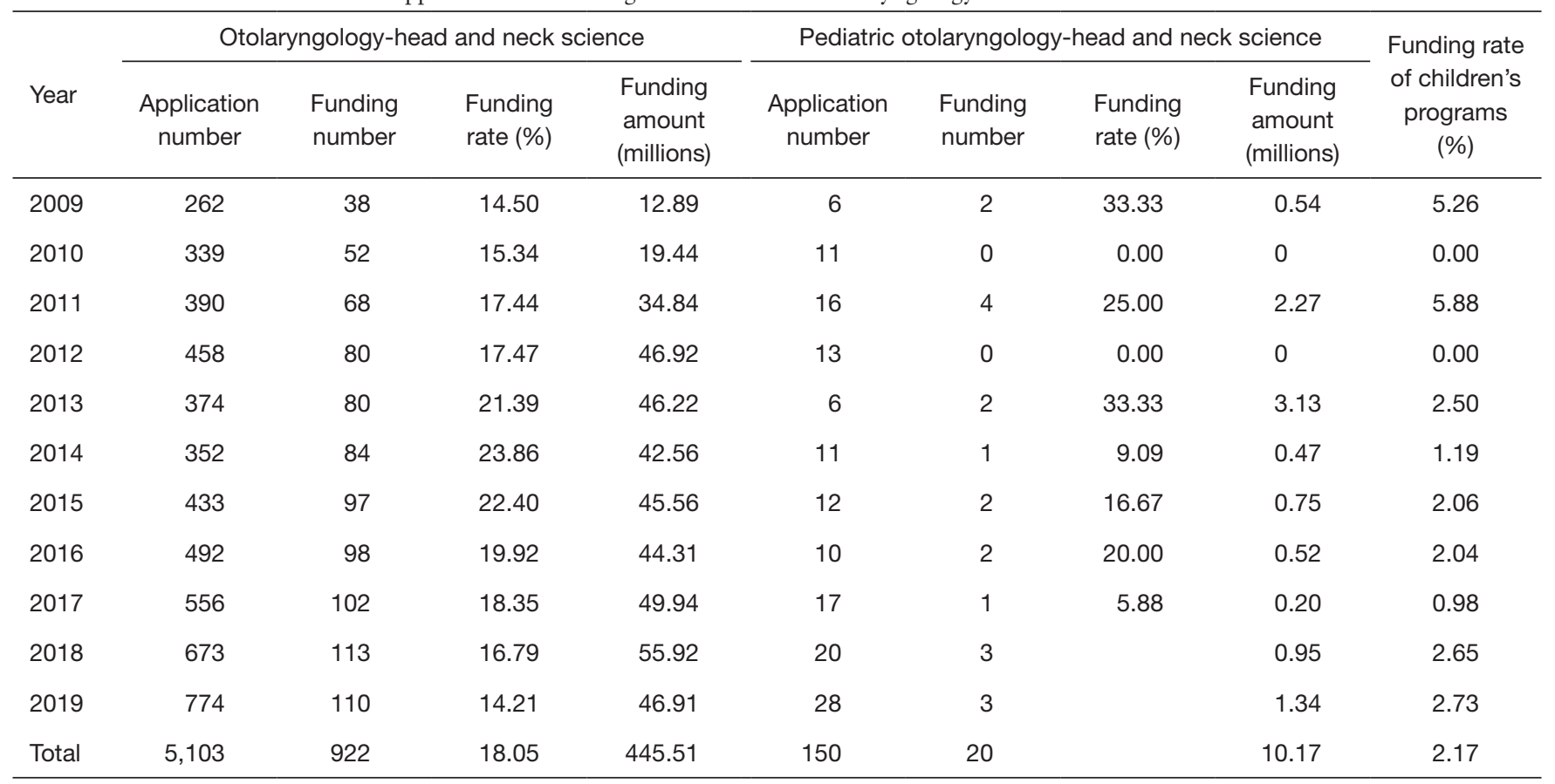

NSFC, National Natural Science Foundation of China.

the dominant research units were relatively concentrated. All the home institution, apart from Guangzhou Women and Children's Medical Center and Beijing Children's Hospital affiliated to Capital Medical University, which are women's and children's specialist hospitals and children's specialist hospitals respectively, were general hospitals for adults (Figure 1).

According to the name and key words of the project, the application and funding status of the project were analyzed according to children's otology, nasology, laryngology, and head and neck science (Table 4, Figure 2).

From 2009 to 2019, there were 88 applications for children's otology- and hearing-related research, with a funding amount of 7.9 million yuan, accounting for $58.67 \%$ of the applications for pediatric otolaryngologyhead and neck science (Figure 2). Most of the applications were related to cochlear implants, deafness genes and mechanisms, and hearing aids and rehabilitation. There 
Table 3 Applications to and funding from the NSFC for otolaryngology-head and neck science in different fields (2009-2019)

\begin{tabular}{|c|c|c|c|c|c|c|c|c|c|c|}
\hline \multirow{2}{*}{$\begin{array}{l}\text { Application } \\
\text { code }\end{array}$} & \multirow[b]{2}{*}{ Field } & \multicolumn{4}{|c|}{ Otolaryngology-head and neck science } & \multicolumn{4}{|c|}{$\begin{array}{l}\text { Pediatric otolaryngology-head and neck } \\
\text { science }\end{array}$} & \multirow{2}{*}{$\begin{array}{c}\text { Funding } \\
\text { rate of } \\
\text { children's } \\
\text { programs } \\
\text { (\%) }\end{array}$} \\
\hline & & $\begin{array}{l}\text { Application } \\
\text { number }\end{array}$ & $\begin{array}{l}\text { Funding } \\
\text { number }\end{array}$ & $\begin{array}{l}\text { Funding } \\
\text { rate (\%) }\end{array}$ & $\begin{array}{l}\text { Funding } \\
\text { amount } \\
\text { (millions) }\end{array}$ & $\begin{array}{l}\text { Application } \\
\text { number }\end{array}$ & $\begin{array}{l}\text { Funding } \\
\text { number }\end{array}$ & $\begin{array}{l}\text { Funding } \\
\text { rate }(\%)\end{array}$ & $\begin{array}{l}\text { Funding } \\
\text { amount } \\
\text { (millions) }\end{array}$ & \\
\hline H1301 & $\begin{array}{l}\text { Olfactory nose } \\
\text { and vestibular } \\
\text { diseases }\end{array}$ & 1,216 & 248 & 20.39 & 112.41 & 28 & 4 & 14.29 & 1.15 & 1.61 \\
\hline H1302 & $\begin{array}{l}\text { Throat and neck } \\
\text { disorders }\end{array}$ & 462 & 67 & 14.50 & 27.16 & 23 & 2 & 8.70 & 1.12 & 2.99 \\
\hline H1303 & $\begin{array}{l}\text { Ear and lateral } \\
\text { skull base } \\
\text { disease }\end{array}$ & 497 & 82 & 16.50 & 36.09 & 14 & 2 & 14.29 & 0.54 & 2.44 \\
\hline H1305 & $\begin{array}{l}\text { Genetic and } \\
\text { developmental } \\
\text { diseases of } \\
\text { otolaryngology- } \\
\text { head and neck }\end{array}$ & 488 & 112 & 22.95 & 55.92 & 20 & 3 & 15.00 & 1.39 & 2.68 \\
\hline H1306 & $\begin{array}{l}\text { New technology } \\
\text { for diagnosis } \\
\text { and treatment in } \\
\text { ENT diseases }\end{array}$ & 247 & 18 & 7.29 & 8.92 & 7 & 0 & 0.00 & 0 & 0.00 \\
\hline
\end{tabular}

NSFC, National Natural Science Foundation of China; ENT, ear, nose, and throat.

were 14 projects funded in children's otology and hearingrelated research, accounting for $70.00 \%$ of the children's direction to funded projects. The funded grants focused on the research of cochlear implants and genetics and mechanisms of deafness. Among the funded projects, there were 4 studies on the genes and mechanisms of deafness and 6 projects on cochlear implant prognosis and rehabilitation; meanwhile, the development and clinical application of speech audiometry, fetal precursor cells immortalized in the inner ear, cochlear nerve hypoplasia, and vestibular central nerve toxicity research all had 1 funded project each. In all, 25 children's nasology projects applied for funding, accounting for $16.67 \%$ of the total applications for pediatric otolaryngology-head and neck science. Four projects related to children's nasology were funded (all funded in 2015) with a funding amount of 1.15 million yuan. The research directions were disease regulation and pathogenesis of allergic rhinitis. There were 30 children's throat disease applications, accounting for $20 \%$ of the applications for pediatric otolaryngology-head and neck science. There were also applied for obstructive sleep apnea syndrome (OSAS), adenoid hypertrophy, and tonsil hypertrophy. In OSAS, the disease mechanism of children's OSAS and OSAS-related cognitive changes were the main focus. Only 1 project associated with OSAS in children's cognitive behavior disorder was funded in 2011, with the total amount given being 570,000 yuan. For research in laryngeal papilloma and lymphatic vascular malformation, there were 4 and 3 applications respectively. Of these, 2 laryngeal papilloma projects were funded, and these were related to the genetic polymorphism and apoptosis mechanism of the disease, with a total funding amount of 550,000 yuan. 


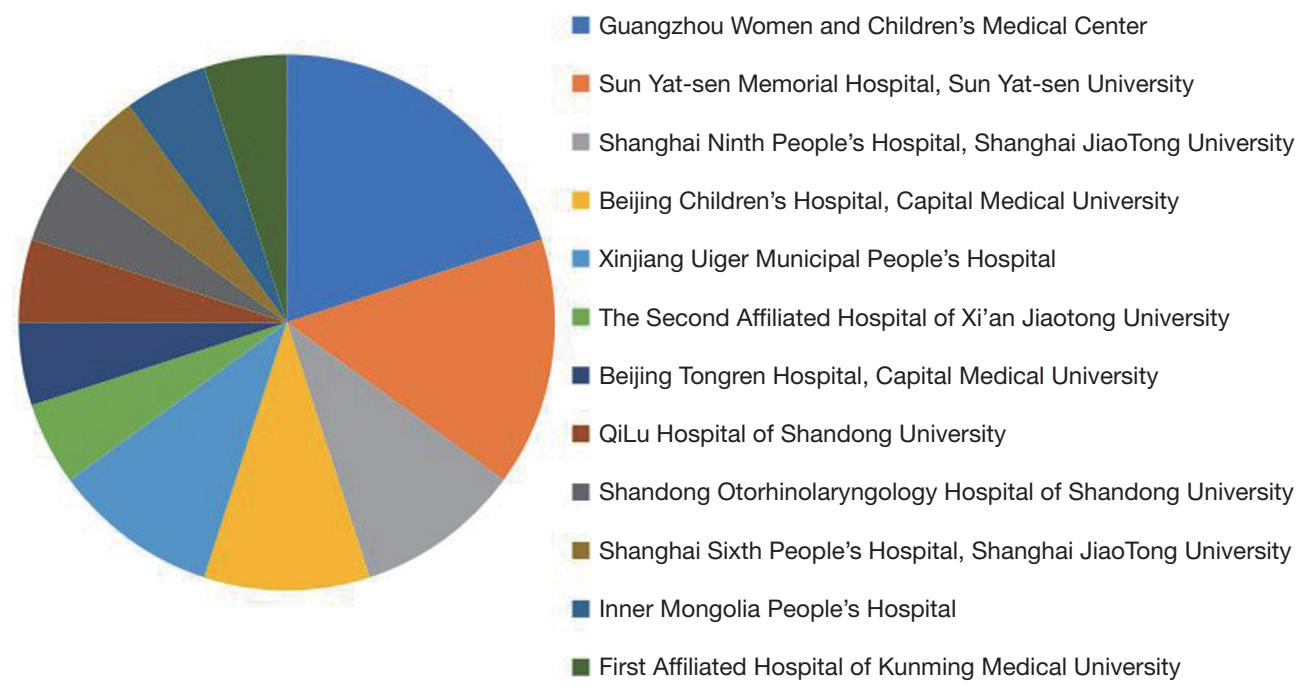

Figure 1 Distribution of funded projects in pediatric otolaryngology-head and neck science.

\section{Discussion}

Pediatric otolaryngology-head and neck science is an emerging discipline of the 21 st century. With the strong support and promotion of the state, clinical research in children's ENT, head and neck surgery, and other subspecialties has been further developed. From 2009 to 2019, pediatric otolaryngology-head and neck science accounted for $2.92 \%$ of the total applications of otolaryngology-head and neck science $(150 / 5,130)$. The funded projects accounted for $2.17 \%$ of the total (20/922), and the amount of funding accounted for $2.28 \%$ of the total given ( $\$ 10.17$ million $\$ \$ 445.509$ million). The number of funded projects in the field of pediatric otolaryngology-head and neck science did not exceed 4 per year. Compared with the $18.07 \%$, funding rate of otolaryngology-head and neck science, the funding rate of pediatric- otorhinolaryngology was only $13.33 \%$, which was lower than the overall level of the discipline. In terms of the types of projects applied for, there were no applications to talent projects such as the Outstanding Youth Science Foundation Project, the National Outstanding Youth Science Foundation Project, and the Innovative Research Group Project in the field of pediatric otolaryngology-head and neck science. Furthermore, there were no applications for major projects such as key projects, major projects, major research projects, and key international (regional) cooperative research projects. The above data fully indicate that the basic research in the field of pediatric otolaryngology-head and neck science is still in its initial stage.
There are only a few institutions that are involved in the basic research of pediatric otolaryngology-head and neck science, and the dominant research institutions are relatively concentrated. The supporting institution with the highest funding rate is Shanghai Jiao Tong University (29.8\%). In pediatric otolaryngology-head and neck science projects supporting institution, $70 \%$ (14 projects) of the project directors are at adult general hospitals, only $20 \%$ (4 projects) are at children's hospitals (Guangzhou Women and Children's medical center), and 10\% (2 projects) work in children's specialized hospitals (Beijing Children's Hospital, Capital Medical University). It should be noted that the funded projects in the field of pediatric otolaryngologyhead and neck science are mainly focused on the extension of adult research and ideas. Pediatric otolaryngology-head and neck science research has always been confined to the "three inflammations and deafness", namely, rhinitis, otitis media, tonsillitis, and deafness. In recent years, the discipline has been developing vigorously, with subdivision and continuous expansion of the range of diagnosis and treatment. Children's ENT, head and neck surgery, vertigo, voice, sleep medicine, and audiology departments have gradually formed disciplines with corresponding population characteristics, which have promoted the development of in-depth basic research.

From 2009 to 2019, the funding rate in the disciplines of pediatric otolaryngology-head and neck science were markedly lower than the overall level of the subject. On the other hand, funding rates of otolaryngology-head and neck disease inheritance and the development of related diseases 
Table 4 The application and funding overview of pediatric otolaryngology-head and neck science

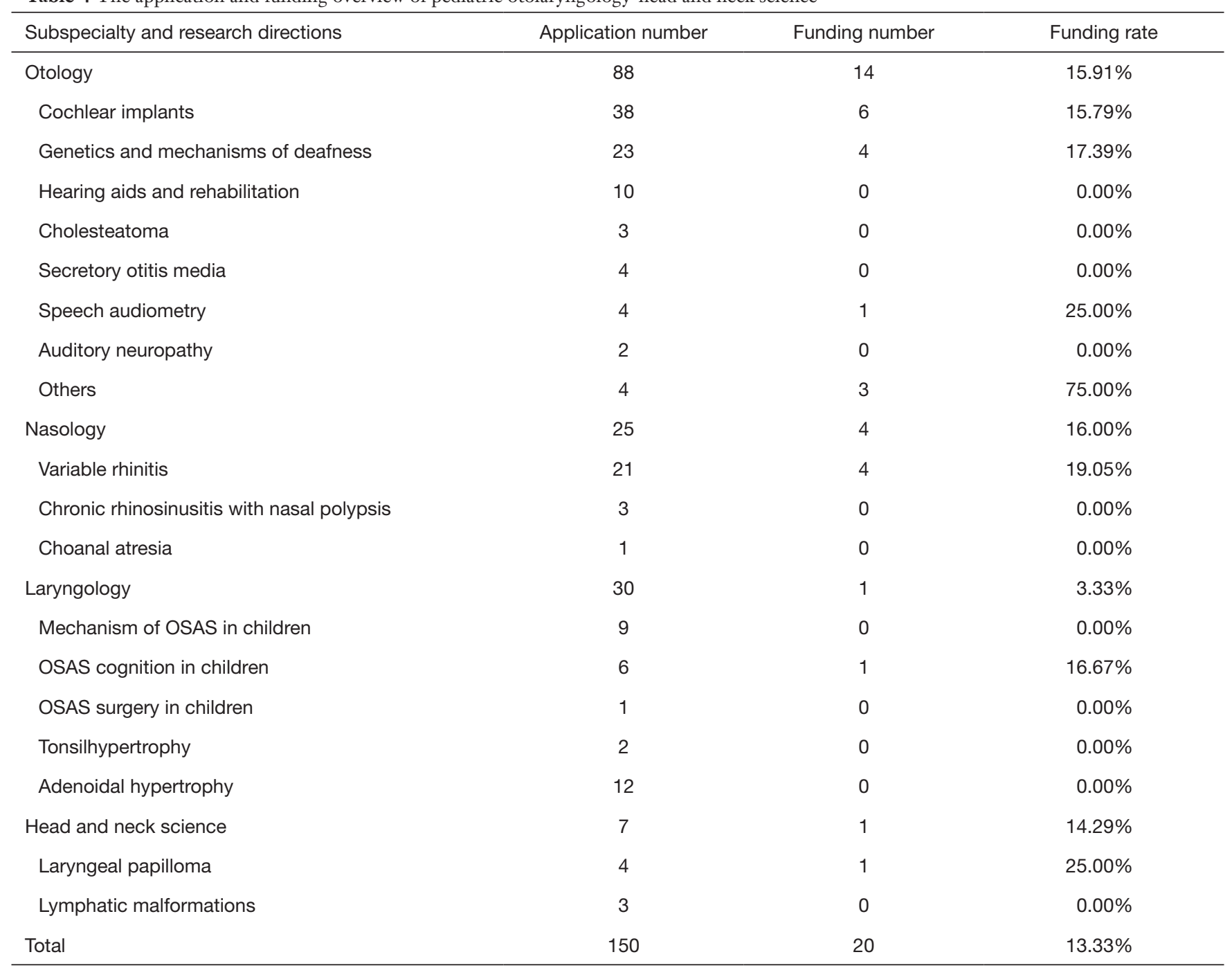

OSAS, obstructive sleep apnea syndrome.

and other scientific problems, including ear, lateral skull base, sense of smell, nasal, and vestibular diseases remained unchanged. As the mechanism of disease, genetic and developmental issues, nasal disease research, and otology and hearing disorders in children's research, occupy the dominant position in the study, the scholars in the field should fully absorb the adult otolaryngology-head and neck scientific ideas and achievements of basic research, and combine them with the characteristics of children's growth, development, and individual character, in the integration of the "difference" and "common" approach. More acute discoveries in ENT and the head and neck scientific field are needed. From 2009 to 2019, the funding rate of pediatric otorhinolaryngology in all sub disciplines was significantly lower than the average level of the discipline, but the funding rate of other otorhinolaryngology related diseases was the same as the overall funding rate of the discipline. It indicating the mechanism research of disease genetics and development, rhinology diseases research and otology disease research are in a dominant position. Scholars in pediatric otorhinolaryngology may "stand on the shoulders of predecessors" to learning from the ideas and achievements of otorhinolaryngology in adults. Combined with the characteristics and individuality of children's growth and development, and under the integrated thinking of "difference" and "generality", the breakthrough point of basic research in pediatric otorhinolaryngology is found more acutely. It is worth noting that the projects related 

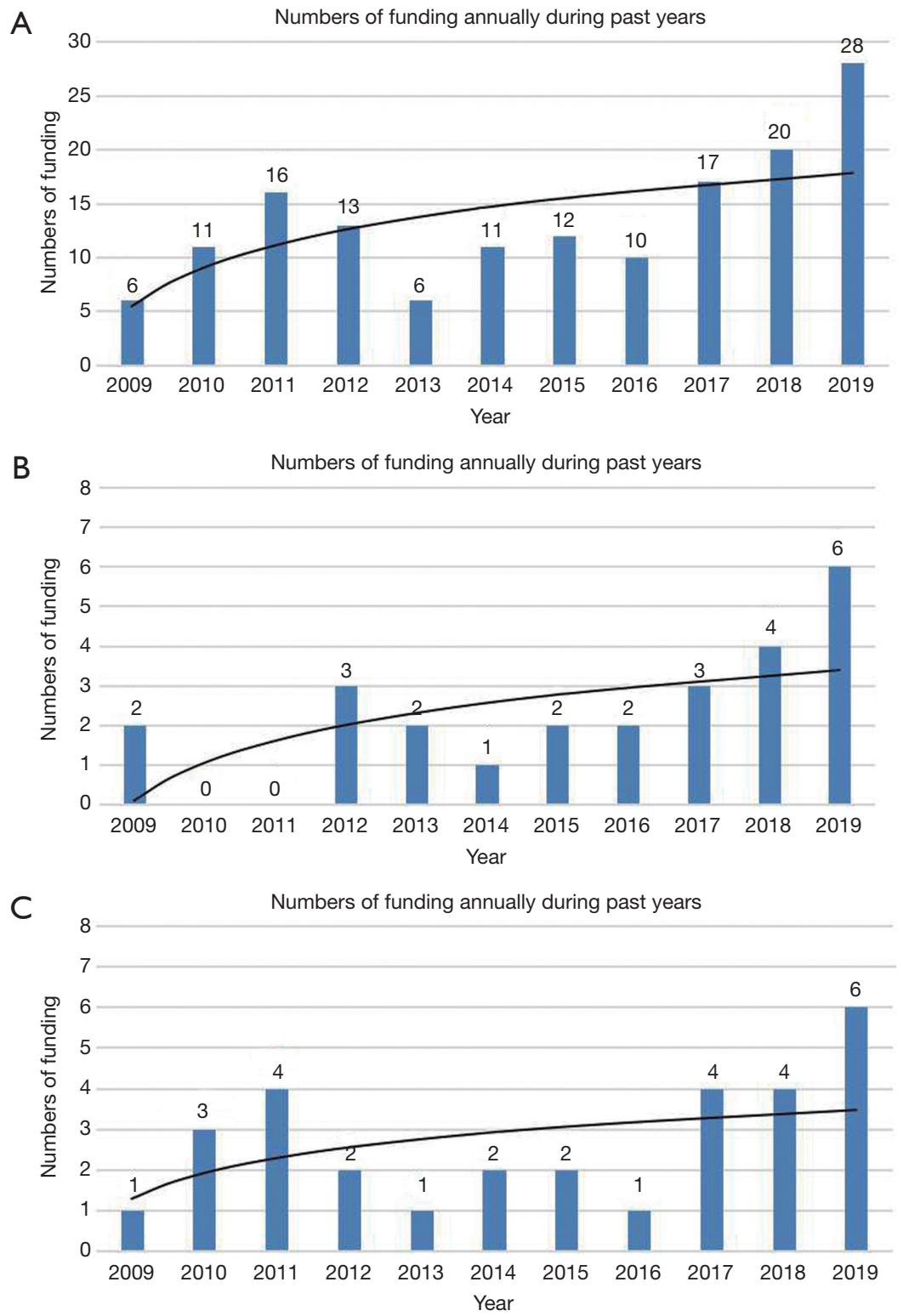

Figure 2 The number of applications for pediatric otorhinolaryngology. (A) The number of applications for children's otology; (B) the number of applications for children's nasology; (C) the number of applications for children's laryngology.

to the new technology for diagnosis and treatment of otolaryngologic diseases are very low. There is even no project was funded in pediatric otorhinolaryngology. It is hoped that under the guidance of clinical problems, scholars will make use of multi-disciplinary cooperation and interdisciplinary medical engineering to carry out interdisciplinary fusion research, so as to promote the development of new technology on diagnosis and treatment of pediatric otorhinolaryngology. It is worth noting that the new technology-related projects and ear disease diagnosis and treatment in adults and especially children are relatively low, and no projects in related subdisciplines have been funded. It is hoped that under the guidance of clinical problems, scholars will make use of multidisciplinary cooperation and the crossover of medical and industrial fields to conduct interdisciplinary integration research, so as to promote the in-depth research of new technologies for the diagnosis and treatment of pediatric otolaryngology- 
head and neck diseases.

From 2009 to 2019, the number of applications and funding given for pediatric otology was the highest in pediatric field, and the number increased yearly, mainly from applications in cochlear implants, genetics and mechanisms of deafness, and hearing aids and rehabilitation. The manifestations of anatomy, physiology, pathology and clinical diseases in children's ear department have their own characteristics. Strengthening the basic research on the mechanism children's hearing impairment is expected to bring light to treatment in the future (3). At the same time, it is hoped that scholars can learn from the experience of basic scientific research on otolaryngology-head and neck science in adults, and actively explore the neurological mechanisms of auditory language ability, the plasticity of auditory cortex, the auditory circuit and neural network, and the relationship between auditory ability and cognitive development in infants.

There were 4 projects in children nasology research, and all of them focused on allergic rhinitis, and disease mechanisms of pathogenesis, regulation, and related research. In view of the disease's large population, its general susceptibility, its diversity and complexity, and the relatively mature research system of adults with the disease, more efforts should be devoted to the in-depth research of the pediatric version of this disease. Congenital nasal malformation in children, such as congenital postnasal atresia, involves upper airway obstruction in neonates, and is a critical disease which has attracted increasing attention from both clinical and basic research. However, there is still no research on its pathogenesis, genetic characteristics, and prognostic factors, and thus further study, based on previous exploration, is warranted.

OSAS is the most serious diseases in sleep-related breathing disorders, and its related research is mainly focused on immunity, cell factors, vascular endothelial cell function, and changes in airway fluid mechanics (4). However, thus far, no pediatric OSAS studies have been funded, which suggests that the basic research on children's laryngeal diseases, especially OSAS, is still in its infancy. Considering the continuous changes of children's growth and development and the special condition of immune organs during this stage, it is suggested that scholars can make full reference to the pattern and layout framework of relevant studies on adults, and conduct indepth research with consideration of the characteristics of children. In addition, pediatric OSAS leads to long- term chronic hypoxia and $\mathrm{CO}_{2}$ accumulation, which causes a series of complications. At present, more attention is being paid to cognitive impairment complications with interdisciplinary studies being conducted on neuroscience. Other complications such as cardiovascular disease, growth and development lag, and facial changes, have garnered less attention and can be considered as nascent ideas for future study. Adenoid and tonsillar hypertrophy is the primary cause of OSAS in children, and the adenoids, as an immune organ unique to children, have attracted much attention. The gene variation, immune regulation, microbiology, fluid dynamics, and etiological mechanism of OSAS related to the adenoids will remain the key research directions of the future.

The research on pediatric head and neck science has mainly focused on congenital malformations and benign tumors, and laryngeal papilloma and lymphatic vascular malformations. Project applications related to these fields mainly centered on immune mechanism and immunotherapy, with 1 project being funded in 2019. It will also persist as a sustainable exploration and attract attention in the future. The clinical treatment of refractory lymphatic vascular malformations is extremely challenging, with the existing treatment of major injuries entailing numerous complications and challenges in complete resection. At present, the basic research on children's lymphatic malformations is still in the initial stage of exploration. Currently, the development of pediatric otolaryngology head and neck surgery in different regions of China is quite unbalanced, which is also one of the reasons for the weak basic level. The main reason is the unbalanced input of scientific research due to the huge economic disparity. It is not easy to solve the problem in short time. However, several planning are being designed by NSFC. For example, the special programme might be set up for this area. Besides, the types of regional funds or joint funds could also be attempted. Anyway, the lack of basic research support for these clinical problems needs to be addressed, and more funding should be provided in the future.

This study has several limitations. It should be mentioned that there are other factors that can show the status of basic research on pediatric otolaryngology, such as the numbers of researchers, the annual academic papers published, the funding data granted by the National Health Commission and even the annual science and technology award granted by the government. Therefore, multi-dimension evaluation are needed in the future studies. 


\section{Conclusions}

Basic research is the driving force for the development of the discipline. The application and funding of NSFC in the last ten years indicates that the basic research level of pediatric otolaryngology-head and neck science in China is weak and lags behind the overall level of the discipline. There are relatively few researchers engaged in the basic scientific research of pediatric otolaryngology-head and neck science. The dominant research units are relatively concentrated a small number of regions, with most of the funded research projects emerging from adult research and radiating from the overall strength of general hospitals. The basic research of children's ear science is relatively advanced in each subspecialty, so the basic research of children's unique congenital and hereditary diseases should be further strengthened. On the basis of learning from adult nasal science, the research on allergic rhinitis and OSAS should pay attention to the integration of both differences and commonalties, and focus on strengthening the research on disease mechanism. Undoubtedly, The Natural Science Foundation will continue in its unique role of supporting the construction of disciplines, increasing funding for these disciplines, and encouraging scholars in the field of otolaryngology-head and neck science to pay more attention to basic research in pediatric fields. Scholars in the field of pediatric otolaryngology-head and neck science should learn from the existing research foundations in the discipline, conduct in-depth research on the scientific issues in this field, form new theories, explore new research directions, and promote the basic research and clinical level improvement of children's otorhinolaryngology-head and neck science.

\section{Acknowledgments}

Funding: None.

\section{Footnote}

Data Sharing Statement: Available at http://dx.doi. org/10.21037/atm-20-6487

Conflicts of Interest: Both authors have completed the ICMJE uniform disclosure form (available at http://dx.doi. org/10.21037/atm-20-6487). The authors have no conflicts of interest to declare.

Ethical Statement: The authors are accountable for all aspects of the work in ensuring that questions related to the accuracy or integrity of any part of the work are appropriately investigated and resolved.

Open Access Statement: This is an Open Access article distributed in accordance with the Creative Commons Attribution-NonCommercial-NoDerivs 4.0 International License (CC BY-NC-ND 4.0), which permits the noncommercial replication and distribution of the article with the strict proviso that no changes or edits are made and the original work is properly cited (including links to both the formal publication through the relevant DOI and the license). See: https://creativecommons.org/licenses/by-nc-nd/4.0/.

\section{References}

1. $\mathrm{Wu} \mathrm{H}, \mathrm{Lv} \mathrm{J}$. History and progress of otolaryngology in children. Chinese Medical Diagest-Otolaryngology 2013;28:2-4.

2. Li WY, Ni WL, Zhang XB. Application and funding status of otorhinolaryngology head and neck surgery research projects funded by National Natural Science Foundation of China from 2009 to 2019. Zhonghua Er Bi Yan Hou Tou Jing Wai Ke Za Zhi 2020;55:47-55.

3. Gao X, Tao Y, Lamas V, et al. Treatment of autosomal dominant hearing loss by in vivo delivery of genome editing agents. Nature 2018;553:217-21.

4. Certal V, Catumbela E, Winck JC, et al. Clinical assessment of pediatric obstructive sleep apnea: a systematic review and meta-analysis. Laryngoscope 2012;122:2105-14.

(English Language Editor: J. Gray)

Cite this article as: Liu Y, Zhang X. The current state and future prospects of the fundamental research on pediatric otolaryngology and head and neck science: an analysis of application and funding data of the National Natural Science Foundation of China from 2009 to 2019. Ann Transl Med 2020;8(20):1287. doi: 10.21037/atm-20-6487 